\title{
STUDY ON CALIBRATION METHOD OF HYDRAULIC BOLT STRETCHER
}

\author{
T. Fang ${ }^{1}$, Y. Jia ${ }^{1}$, H. Xu ${ }^{1}$, H. Zhang ${ }^{1}$, W. Liu ${ }^{1}$ \\ ${ }^{1}$ Liaoning Province Institute of Measurement, Shenyang, China, 757573199@qq.com
}

\begin{abstract}
:
Bolt hydraulic tensioner is ideal equipment for bolt fastening and disassembly. Compared with traditional method, it has incomparable advantages. Bolt hydraulic tensioner has been widely used in wind power, nuclear power, aerospace, steel, petrochemical and other major fields. In this paper, two methods of calibrating the hydraulic stretcher are proposed, and the problems that should be paid attention to in the process of calibrating the stretcher are analyzed in detail, it can be used for reference in the calibration of hydraulic stretcher.
\end{abstract}

Keywords: bolt hydraulic stretcher; calibration method; pressure gauge; standard dynamometer; fitting equation

\section{INTRODUCTION}

The bolt hydraulic tensioner is the ideal equipment for bolt fastening and disassembly, the hydraulic tensioner has the incomparable advantage of the traditional hammer hitting spanner or the method of using the hydraulic spanner. First, the bolt is only subjected to the tensile force while working, eliminating the consumption of friction and screw torque, the tensile force is determined by the elongation, tensile strength and yield coefficient of the material. Working through the high-pressure oil pump to provide tensile force for the bolt, in the elastic deformation and slight plastic deformation of the bolt will be stretched, so that the diameter of the bolt smaller, so that the nut more easy to tighten or loosen, do not lose the bolt and nut. Second, the bolt tensioner on the connector can ensure the connector axial force uniform, high reliability of the connection, can work multiple bolts at the same time, so as to ensure the synchronization of bolt pretightening force. Third, bolt hydraulic tensioner is small and flexible, greatly reducing the occupancy rate of space. Because of these advantages, hydraulic stretcher has been widely used in wind power, nuclear power, aerospace, steel industry, heavy machinery, petrochemical and other major fields, especially in the situation of serious environmental pollution or restricted working space, the hydraulic stretcher plays an irreplaceable role, as Figure 1.
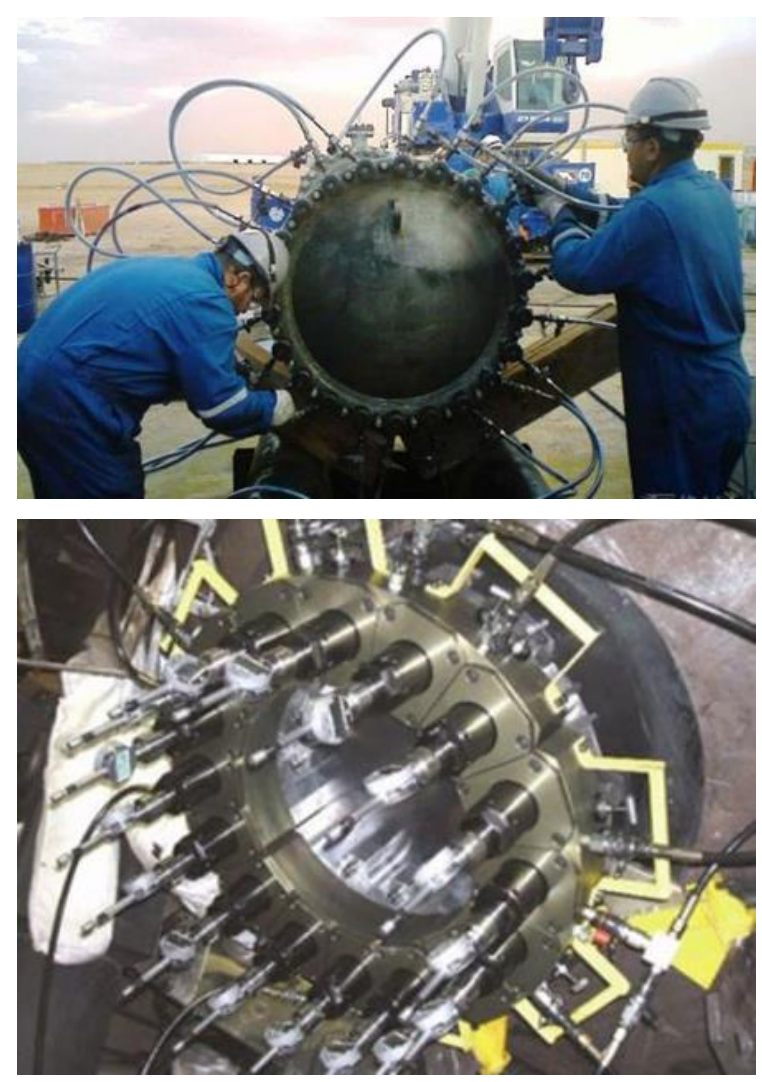

Figure 1: Application of stretcher in wind power and nuclear power industry

\section{CALIBRATION METHOD}

Whether the tensioner can provide accurate pretightening force is closely related to whether the bolt hydraulic tensioner calibration method is correct or not. At present, most of the bolt hydraulic tensioner calibration work is completed by the manufacturer in China, the authenticity, accuracy and reliability of the data cannot be certified and approved by the Authority. There are few domestic literatures on the calibration method of the bolt stretcher, and few studies on the calibration device of the bolt stretcher. How to solving the problem of bolt tensioner calibration is the most important work in the development of bolt retightening technology. 
At present, there is no technical regulation for bolt hydraulic tensioner in our country. The calibration is generally referred to [1], but this standard is only limited to the general technical index, the discussion on the testing method and testing procedure of the hydraulic stretcher is not only limited but also not completely suitable for the calibration of the instrument. Especially in recent years the number of domestic manufacturers of the equipment is increasing, the use of such equipment is also rapidly increasing, the performance is uneven, so product quality is extremely important. If the calibration procedure could be better specified, the calibration of the bolt stretcher would be improved. Such procedural changes might include: determine whether to meet the requirements of technical indicators, measuring instruments and auxiliary equipment, how to select and use standards, so that the calibration results will make enterprises and users feel more secure.

Based on many years of experience of bolt tensioner calibration, the authors summarize a set of hydraulic tensioner calibration device. The calibration device of hydraulic stretcher is usually composed of high-pressure pump, high-pressure hose, pressure gauge, standard dynamometer or special working dynamometer (testing machine, force standard machine). Calibration methods are mainly divided into two methods, the difference between the two methods is the way to obtain the tensile force of the tensioner:

1. Collection of tensile force by a special working dynamometer: the output force is exerted by a high-pressure pump through a series connection of a hydraulic stretcher with a special working dynamometer (a testing machine or a force standard machine), read the readings of special working dynamometer (testing machine, force standard machine) and pressure gauge, and establish the corresponding table of their relationship.

2. The tension force is collected by the standard dynamometer: the hydraulic tensioner is connected with the standard dynamometer mainly by the method of reaction force, the output force is exerted by the high pressure pump, the readings of the standard dynamometer and the pressure gauge are read, and the corresponding tables of the relationship between the two are established, as Figure 2.

Comparing the two methods, the first method needs the purchase of special working force measuring machines (testing machines, force standard machines) which meet the requirements. The accuracy depends on the accuracy of testing machines and force standard machines and the measuring range needs to reach $3 \mathrm{MN}$. The second method requires only a standard dynamometer and related reaction equipment to meet the requirements, the investment is small, and the metrological and verification departments have it, it is easy to use the second method to develop the bolt hydraulic stretcher.

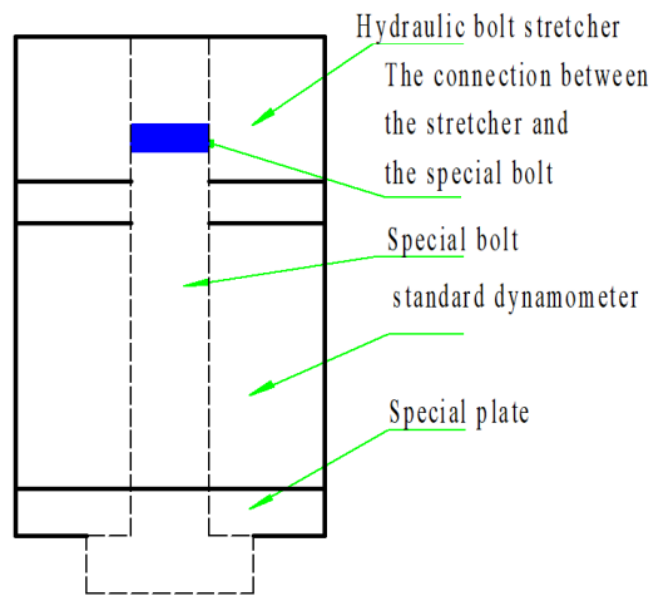

Figure 2: Schematic diagram of standard dynamometer calibration stretcher

\section{POINTS TO NOTE IN THE TENSIONER CALIBRATION PROCESS}

\subsection{Pressure Gauge Selection}

Pressure gauges are common measuring instruments. The selection of pressure gauges should be based on the operational requirements and on the premise of meeting the technological requirements. Comprehensive consideration should be given in the principle of economy and practicality, to achieve a reasonable choice of accuracy, range, type.

Accuracy grade: the theoretical error of the tensioner is not more than $3 \%$, so in theory the pressure gauge with accuracy grade not less than 1.6 can be selected, it is recommended to use a precision pressure gauge of not less than 0.4 grades. The reasons for the analysis are as follows. The data obtained by using the two pressure gauges that have been certified are shown in Tables 1 and 2 .

Table 1: Calibration results using class 1.6 pressure gauges

\begin{tabular}{|c|c|c|c|}
\hline $\begin{array}{c}\text { Indicator } \\
\text { reading } \\
\text { / MPa }\end{array}$ & $\begin{array}{c}\text { Force } \\
\text { / } \mathbf{~} \mathbf{N}\end{array}$ & $\begin{array}{c}\text { Interpolation } \\
\text { value } \\
\text { / MPa }\end{array}$ & $\begin{array}{c}\text { Interpolation } \\
\text { error } \\
\text { / \% }\end{array}$ \\
\hline 10 & 47.1 & 10.43 & 4.4 \\
\hline 20 & 90.9 & 19.18 & -4.1 \\
\hline 40 & 197.2 & 40.54 & 1.4 \\
\hline 60 & 292.6 & 59.85 & -0.3 \\
\hline 80 & 392.6 & 80.24 & 0.4 \\
\hline 100 & 486.6 & 99.55 & -0.5 \\
\hline 120 & 586.4 & 120.19 & 0.2 \\
\hline
\end{tabular}


Table 2: Calibration results using class 0.4 pressure gauges

\begin{tabular}{|c|c|c|c|}
\hline $\begin{array}{c}\text { Indicator } \\
\text { reading } \\
\text { / MPa }\end{array}$ & $\begin{array}{c}\text { Force } \\
\text { / kN }\end{array}$ & $\begin{array}{c}\text { Interpolation } \\
\text { value } \\
\text { / MPa }\end{array}$ & $\begin{array}{c}\text { Interpolation } \\
\text { error } \\
\text { / \% }\end{array}$ \\
\hline 10 & 48.1 & 9.91 & -0.9 \\
\hline 20 & 97.9 & 19.99 & -0.1 \\
\hline 40 & 198.1 & 40.28 & 0.7 \\
\hline 60 & 293.7 & 59.77 & -0.4 \\
\hline 80 & 393.8 & 80.28 & 0.4 \\
\hline 100 & 487.7 & 99.59 & -0.5 \\
\hline 120 & 587.3 & 120.18 & 0.2 \\
\hline
\end{tabular}

As can be seen from Tables 1 and 2, the interpolation error of $10 \mathrm{MPa}$ in Table 1 is $4.4 \%$, and that of $40 \mathrm{MPa}$ is $1.4 \%$. The interpolation error of $20 \mathrm{MPa}$ has a sudden change, while the data in Table 2 are all less than $1 \%$. The same inspection qualified two pressure gauges, but the accuracy level is different, 1.6 pressure gauges in less than $1 / 3$ of the range. The occurred beating data are not accurate and cannot be used. In order to ensure the accuracy of the measurement, the minimum working pressure should not be less than $1 / 3$ of the measuring range and a high accuracy pressure gauge should be used. Therefore, it is recommended to use a precision pressure gauge of 0.4 grade.

Also of special concern is that the equipment manufacturers do not generally sell the tensioner pressure gauge, tensioner use reference to the theoretical value provided by the manufacturer table or after calibration certificate metrology verification department. Through many experiments, it is found that the final value of load is not the same even if different gauges with the same accuracy grade are used to calibrate the same tensioner. Therefore, the authors recommend that the manufacturer of the tensioner should equip each tensioner with one or even two pressure gauges. One should be used for work, and when one of the pressure gauges is damaged, the other should be used as a backup pressure gauge, both pressure gauges are calibrated during the tensioner calibration to improve accuracy, safety, and sudden failure of the tensioner.

\subsection{Standard Dynamometer Selection}

Standard dynamometers below $1 \mathrm{MN}$ are recommended to be used at accuracy grade 0.1 or above, and those above $1 \mathrm{MN}$ are recommended to be used at level 0.3 or above. Nowadays, standard dynamometers are developing rapidly; most of the standard dynamometers can reach the accuracy grade recommended by the authors, which is helpful to improve the accuracy of the tensioner calibration.

\subsection{High-Pressure Pump Selection}

Recommend the use of pneumatic hydraulic pump, pneumatic hydraulic pump with a safe and reliable, high output pressure, easy to operate, continuous start-stop, unrestricted and other advantages, especially suitable for the tensioner calibration.

\section{DATA PROCESSING}

On data processing, it is recommended not only to give the indicator process value corresponding to the load value, it is also best to give the two corresponding quadratic curve fitting equations, the advantage of the fitting equation is that the corresponding output value of any input point in the measuring range can be obtained. It is convenient for users to face different types of bolts or to develop new products; the calibration certificate issued by Liaoning Institute will be accompanied by the corresponding calibration equations and charts of the instrument and equipment. The fitting equation and chart are shown in Figure 3.

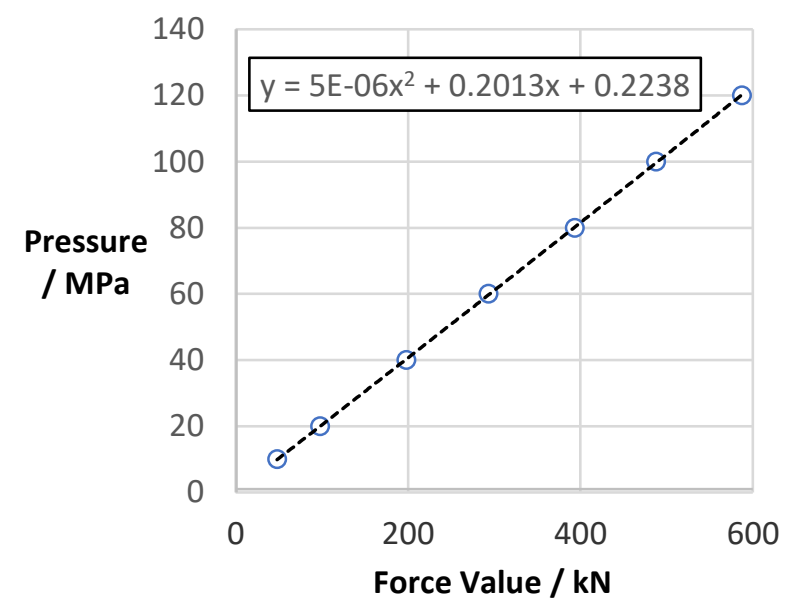

Figure 3: Fitting equation of tensioner

\section{SUMMARY}

Through the introduction of bolt hydraulic stretcher and its application field, this paper puts forward two methods to calibrate the stretcher, analyzes the problems needing attention in the process of calibration, and gives a detailed discussion and recommendation, it can be used for reference in the calibration of bolt hydraulic tensioner.

\section{REFERENCES}

[1] JJG 621-2012, Verification Regulation of Hydraulic Jacks, AQSIQ, China, 2012. 